\title{
Combined Analysis of C-reactive Protein in Pleural Fluid and Serum is Effective in the Differential Diagnosis of Exudative Pleural Effusions
}

\author{
Shuo-yao Qu \\ Xijing Hospital \\ Yong Zhang \\ Xijing Hospital \\ Shuo Wu \\ Xijing Hospital \\ Ming-ming Wang \\ Xijing Hospital \\ Ling-li Liu \\ Xijing Hospital \\ Xue-min Yang \\ Xijing Hospital \\ Hui-liang Shan \\ Xijing Hospital \\ Juan-li Yang \\ Xijing Hospital \\ Pei Chen \\ Xijing Hospital \\ Xin-Yu Ti ( $\sim$ TiXY_pccm@21cn.com ) \\ XiJing Hospital
}

\section{Research}

Keywords: C-reactive protein, Procalcitonin, Pleural effusion, Empyema, Diagnostic effectiveness

Posted Date: March 18th, 2021

DOI: https://doi.org/10.21203/rs.3.rs-314757/v1

License: (c) (i) This work is licensed under a Creative Commons Attribution 4.0 International License. Read Full License 


\section{Abstract}

Background: Exudative pleural effusion (EPE) is one of the common pleural manifestations of various diseases. Differential diagnosis of EPE is imperative clinically as it identifies different causes of EPE, thereby, providing effective treatments. Thoracoscopy is a useful tool for differential diagnosis of EPE. However, some patients would refuse thoracoscopic examination due to its invasive nature. In addition, the specificity and sensitivity of existing routine tests of EPE are less satisfying. Therefore, there is a great need to establish an effective method for differential diagnosis of EPE.

Methods: This study was a single-institution retrospective analysis of diagnostic efficiency of C-reactive protein (CRP) and procalcitonin (PCT) between March 2018 and September 2018. Eighty-seven patients diagnosed with EPE were enrolled. All patients underwent diagnostic thoracentesis. And the EPE was examined using biochemical, routine, microbiological, and cytological methods. Pathological cytology detection was of necessity for those with the suspicion of malignant PE. Benign PE comes from patients with pneumonia, empyema and tuberculosis. The levels of CRP and PCT of EPE and serum were measured before the treatment. Correlation analysis and receiver-operating characteristic (ROC) curve analysis were conducted to determine the underlying relationship between levels of CRP and PCT, and differential diagnosis.

Results: Receiver operating characteristic analysis showed that the sensitivity and specificity for the analysis of pleural fluid CRP (p-CRP) are higher (cut-off: 17.55 pg/mL; sensitivity: $75.00 \%$, specificity: $83.90 \%$ ) than that of serum CRP (sCRP, cut-off: $23.90 \mathrm{pg} / \mathrm{mL}$; sensitivity: $71.00 \%$, specificity: $80.4 \%$ ) in the differential diagnosis for EPE. However, the analysis of pleural fluid PCT ( $p-P C T$ ) and serum PCT (s-PCT) didn't demonstrate correlations with EPE. Combined analysis of p-CRP (cut-off: $17.55 \mathrm{mg} / \mathrm{dL}$ ) with s-CRP (cut-off: $23.9 \mathrm{pg} / \mathrm{mL}$ ) showed the highest diagnostic accuracy $(88.4 \%)$ in diagnosing infectious EPE.

Conclusions: The data support the close relationship between combined analysis of p-CRP with s-CRP and effective and accurate differential diagnosis of EPE, due to its higher sensitivity and specificity. However, as a highly sensitive marker to diagnose bacterial infections, neither S-PCT nor P-PCT, showed correlations with the differential diagnosis of EPE.

\section{Introduction}

As one of the common clinical manifestations of pleural-related diseases, exudative pleural effusion (EPE) can be caused by several diseases [1]. Its differential diagnosis depends on the comprehensive routine examinations of EPE, including biochemical examination, enzymology, infection index and pathological cytology [2]. However, the sensitivity and specificity of the above tests are still controversial [3,4]. The etiology of exudative effusion with lymphocyte predominance, which is difficult to be diagnosed, depends on medical pleural biopsy or even surgical thoracoscopy. However, the application of thoracoscopy in differential diagnosis of EPE is clinically limited as some patients would refuse the test due to its invasive nature, potential risk of anesthesia, and expensive medical costs. Besides, the duration of these invasive operations may be prolonged due to series of complicated diagnostic tests. As for the differential diagnosis between tuberculosis- and bacteria-oriented EPE, invasive examination-based biochemistry and etiology tests fail to reach a diagnostic consensus, and in turn lead to a detainment of interventions in early stage. For the patients with malignant pleural disease, rapid diagnosis benefits for minimizing the abuse of antibiotics and reducing medical costs, while the utilization of pathological cytology often needs repeated tests of pleural extraction, which may delay the treatment. Therefore, rapid diagnosis and the corresponding therapies of the pleural effusion in an accurate and effective manner benefits those patients to the utmost extent. 
It has been widely accepted that the analysis of levels of CRP and PCT in the serum are useful to diagnose systemic and focal inflammation diseases. Some researchers have investigated the roles of CRP and PCT in differentiating the etiology of EPE [5]. CRP is an acute-phase protein that is synthesized primarily by hepatocytes in response to many kinds of stimuli from either infectious or non-infectious origin [9]. The expression of CRP in pleural effusion is closely related to the level of s-CRP, which is mainly due to the release of inflammatory factors stimulating the expression of CRP in local capillaries of pleural cavity. The synthesized CRP translocate into the pleural cavity, leading to permeability change in pleura and the formation of EPE [10]. Meanwhile, PCT is a prohormone of calcitonin that is secreted by Ccells of the thyroid gland as a response to hypercalcemia physiologically. Escalation of PCT is now regarded as a useful serological biomarker of bacterial infection [6]. In recent years, some studies explored the diagnostic effectiveness of PCT in serum or pleural effusion, while they drew conflicting conclusions based on multi-center clinical studies, leading to a controversial status for pleural PCT in diagnosing $[7,8]$.

This study aims to evaluate the effectiveness of CRP and PCT in diagnosing EPE and to compare the pleural fluid concentrations of CRP and PCT in patients with EPE bearing various pathologies, benign or malignant. The sensitivity and specificity of the analysis of CRP and PCT were determined.

\section{Materials And Methods Study design}

This study was a retrospective analysis based at a maintained medical records database at the Department of Pulmonary and Critical Care Medicine, Xijing Hospital, Fourth Military Medical University. Fourth Military Medical University Xijing Hospital institutional review board approval was approved for this retrospective clinical study and meta-analysis. Between September 2018 and July 2019, a total of 87 patients aged $\geq 18$ years with EPE according to the Light's criteria were enrolled and analyzed in this study. All patients underwent thoracentesis. A malignant PE was confirmed with cytological cells $₫$ and some patients with malignant pleural effusion with negative cytology were diagnosed by histopathological biopsy of pleura or other organs. The etiologies of pleural effusion were mainly classified into 4 categories: malignant, tuberculosis, parapneumonic effusion, and empyema patients. Our clinicians will give a comprehensive diagnosis of empyema or parapneumonic effusion according to the patient's medical history, clinical manifestations, physical signs, appearance of pleural effusion, routine tests and other results. Tuberculosis EPE was diagnosed if one of the following was positive: granulomatous inflammation seen on the pleural biopsy specimen, acid-fast staining, mycobacterium tuberculosis culture, Gene-Xpert /TB-DNA-PCR positive.

All the cases were divided into mainly 2 categories: infectious or non-infectious effusions. The diagnosis was made by physicians based on the test results and the responses to the treatments.

\section{Procedures}

Thoracentesis was performed on each patient, then all the of pleural fluid samples were subjected to routine examinations (e.g. pH, Rivalta test, total red blood cell, white blood cell, lymphocyte and neutrophil count and rate), biochemical examinations (total protein and glucose), enzymology tests ( $L D H, A D A)$, and microbiological examinations. to detect bacterial infections, smear tests and bacterial culture were conducted Acid-fast staining, TB-DNA-PCR and Gene-Xpert were used for tuberculosis detection. The pathological cytology was used to distinguish EPE from benign or malignant origins. 


\section{Measurement of CRP and PCT levels}

The pleural fluid and peripheral blood ( $4 \mathrm{ml}$ for each) was obtained and centrifuged at 3,500 rpm for $5 \mathrm{~min}$ at $4^{\circ} \mathrm{C}$. The supernatants were collected. The levels of CRP and PCT were determined with "The One Step Test for CRP/PCT kit (colloidal gold)", measured by a Getein1100 fluorescence immunity analyser (Getein Biotech, Inc., Nanjing, China) with a functional assay sensitivity of $0.1 \mathrm{ng} / \mathrm{ml}$. The analyses were performed according to the manufacturers' instructions.

\section{Statistical analysis}

Data are presented as means \pm standard deviation (SD) for data with a normal distribution and as medians with interquartile ranges in parentheses for skewed data. Chi-square test was used to compare the rates. ROC curves were generated by plotting sensitivity against 1-specificity, and the area under the curve (AUC) with $95 \%$ confidence intervals (CI) was calculated. The Youden index was used to identify the cut-off values with potential diagnostic significance. After data collection, statistical analysis of the data was performed using a statistical software package [(SPSS for Windows, version 21.0; SPSS Inc. (IBM SPSS, Chicago, USA)], and $p$-values < 0.05 were considered statistically significant.

\section{Results}

\section{Clinical and biological characteristics of the enrolled patients}

A total of 87 patients were enrolled and analyzed in this study. According to the type of disease, patients were divided into four groups. The benign group included 56 cases: tuberculosis $(33,58.92 \%)$, parapneumonic $(17,30.35 \%)$ and empyema $(6,10.71 \%)$. Although parapneumonic and empyema were differentiated, but in recent literature both of them are grouped under the term "pleural infection" because both conditions are treated in the same manner. The diagnosis of these two diseases depends on the comprehensive judgment of clinicians. There are 31 cases of malignant. The clinical data biological features of the patients are shown in Table 1. This study included 62 men and 25 women with no significant difference in each group. The average age of all the patients was 56 years. There were no differences in terms of age and sex between the four groups (Table 1). 
Table 1

Baseline demographic data and pleural fluid characteristics

\begin{tabular}{|c|c|c|c|c|c|}
\hline & Malignant & Tuberculosis & Parapneumonic & Empyema & $\begin{array}{l}P \\
\text { value }\end{array}$ \\
\hline Age (y, median; range) & $65(21-87)$ & $56(19-95)$ & $55(15-77)$ & $65(36-66)$ & 0.07 \\
\hline Male (n,\%) & $21(67.74 \%)$ & $25(75.76 \%)$ & $11(64.71 \%)$ & $5(83.33 \%)$ & 0.857 \\
\hline \multicolumn{6}{|l|}{$\begin{array}{l}\text { PE conventional } \\
\text { analysis }\end{array}$} \\
\hline $\operatorname{WBC}\left(\times 10^{6} / \mathrm{L}\right)$ & 1290(33-8242) & 1889(180-7310) & $1359(150-9100)$ & $\begin{array}{l}56742(16212- \\
246200)\end{array}$ & $<.001$ \\
\hline $\mathrm{RBC}\left(\times 10^{6} / \mathrm{L}\right)$ & $\begin{array}{l}2890(0- \\
112500)\end{array}$ & $2800(0-54500)$ & $\begin{array}{l}6050(1000- \\
59500)\end{array}$ & $\begin{array}{l}5000(400- \\
260000)\end{array}$ & $<.006$ \\
\hline Lymphocytes (\%) & $70.5(12-93)$ & $88.5(28-98)$ & $38(7-97)$ & $8(2-26)$ & $<0.001$ \\
\hline Neutrophils (\%) & $26(7-88)$ & $12(1-72)$ & $62(3-93)$ & $92(74-98)$ & $<0.001$ \\
\hline \multicolumn{6}{|l|}{$\begin{array}{l}\text { PE biochemical } \\
\text { analysis }\end{array}$} \\
\hline $\begin{array}{l}\text { Total protein (mean } \pm \\
\text { SD, g/L) }\end{array}$ & $41.91 \pm 8.82$ & $45.87 \pm 11.69$ & $39.41 \pm 10.21$ & $50.46 \pm 6.49$ & 0.02 \\
\hline Glucose(mmol/L) & $5.68 \pm 2.26$ & $4.17 \pm 2.73$ & $6.32 \pm 1.86$ & $5.31 \pm 0.32$ & 0.082 \\
\hline LDH (IU/L) & $\begin{array}{l}298(189.5 \\
729)\end{array}$ & $54.29 \pm 34.8$ & $497(236,713)$ & $790(449,2427)$ & $<0.001$ \\
\hline ADA(IU/L) & $18.60(9.8,29.5)$ & $57.50(20.27,79.05)$ & $20.85(15.17,27.53)$ & $3.88(1.00-4.86)$ & $<.001$ \\
\hline \multicolumn{6}{|c|}{$\begin{array}{l}\text { Data are presented as the mean } \pm \text { SD for normally distributed data or as the median (interquartile ranges) for } \\
\text { skewed data; The tuberculosis group }(n=33) \text {, parapneumonic }(n=17) \text {, and empyema }(n=6) \text {. WBC, white blood cell; } \\
\text { RBC, Red blood cell; ADA, adenosine deaminase; LDH, lactate dehydrogenase; }\end{array}$} \\
\hline
\end{tabular}

\section{General characteristics of EPE}

There were significant differences in the number of WBCs among 4 groups: the highest in empyema group [56742 $\left.\times 10^{6} / \mathrm{L}(16212-246200) \times 10^{6} / \mathrm{L}\right]$, followed by tuberculosis group $\left[1889 \times 10^{6}(180-7310) \times 10^{6}\right]$ and parapneumonic

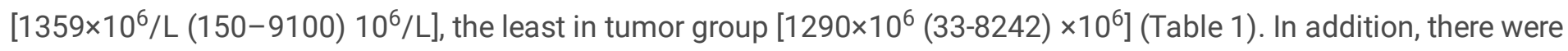
also significant differences of the number of RBCs among 4 groups. Empyema and parapneumonic groups had relatively higher RBCs $\left[6050 \times 10^{6}(1000-59500) \times 10^{6}\right.$ and $\left.5000 \times 10^{6}(400-260000) \times 10^{6}\right]$, tuberculosis and malignant groups were relatively low in RBSs counts $\left[2890 \times 10^{6}(0-112500) \times 10^{6}\right.$ and $\left.2800 \times 10^{6}(0-54500) \times 10^{6}\right]($ Table 1$)$. There were also significant differences in the ratio of neutrophils and lymphocytes. Malignant and tuberculosis groups were with higher lymphocyte cells number and ratio [70.5\% (12-93) \% and 88.5\% (28-98) \%], while empyema and parapneumonic groups were with lower [38\% (7-97) \% and 8\% (2-26) \%] (Table 1). By contrast, malignant and tuberculosis groups had lower neutrophil cells number and ratio [26(7-88) \% and $12 \%(1-72) \%]$, whereas the neutrophil cells number and ratio were higher [62\% (3-93) \% and 92\% (74-98) \%] in empyema and parapneumonic groups (Table 1). 
The biochemical analysis showed that protein, LDH and ADA were significantly different among 4 groups. The level of adenosine deaminase (ADA) in tuberculosis group was much higher $[57.50(20.27,79.05)]$, followed by parapneumonic and malignant $[20.85(15.17,27.53)$ and 18.60(9.8,29.5)]. The level of ADH in empyema group was the lowest [3.88(1.00$4.86)]$. The levels of lactate dehydrogenase (LDH) in empyema and parapneumonic groups were higher $[790(449,2427)$ and $497(236,713)]$.

\section{Pleural fluid levels of CRP, and PCT}

P-CRP levels were significantly higher in empyema and parapneumonic groups, while lower in tuberculous and malignant groups (Fig. 1A). But there were no significant differences between empyema and parapneumonic [54.9 $(28.75,77.85)$ vs. $57.25(40.7,191.63)]$, as well as tuberculous and malignant groups. Unlike CRP in pleural effusion, there were higher levels of s-CRP in benign groups (tuberculous, empyema and parapneumonic) of than that in malignant group [12.9 (5.45-34.70)] (Fig. 1B), but there is no significant difference between tuberculous [44.9(20.35,108.35)], parapneumonic groups [93.9(40.13,162.63)] and empyema [116(49.60,176.73)]. Interestingly, pleural PCT level was similar among four groups (Fig. 1C). As a classical marker of bacterial infection, PCT level is higher in the parapneumonic effusion group compared with that in tuberculosis and malignant group, while there was no significant increase in empyema group (Fig. 1D). It was worth noting that the levels of serum/pleural CRP and s-PCT are significant different between 4 groups, while plural PCT was not. Both of s-CRP and p-CRP were the highest in empyema group, followed by parapneumonic effusion group and tuberculosis group, and the lowest in malignant group. S-PCT was higher in parapneumonic effusion and empyema group, and lower in tuberculosis and malignant group. But there was no significant difference in p-pct among the four groups (Table 2).

Table 2

Levels of CRP and PCT in the pleural fluid and blood

\begin{tabular}{|c|c|c|c|c|c|}
\hline & Malignant & Tuberculosis & Parapneumonic & Empyema & $P$ value \\
\hline \multicolumn{6}{|c|}{$\mathrm{CRP}(\mathrm{mg} / \mathrm{L})$} \\
\hline $\begin{array}{l}\text { Pleural } \\
\text { effusion }\end{array}$ & $11.10(5,14.5)$ & $19(8.75,41.65)$ & $54.9(28.75,77.85)$ & $57.25(40.7,191.63)$ & $<0.001$ \\
\hline Serum & $12.9(5.45-34.70)$ & $44.9(20.35,108.35)$ & $93.9(40.13,162.63)$ & 116(49.60,176.73) & $<0.001$ \\
\hline \multicolumn{6}{|c|}{ РCT(ng/ml) } \\
\hline $\begin{array}{l}\text { Pleural } \\
\text { effusion }\end{array}$ & $0.1(0.1,0.1)$ & $0.1(0.1,0.1)$ & $0.1(0.1,0.365)$ & $0.115(0.1,0.305)$ & 0.094 \\
\hline Serum & $0.1(0.1,0.1025)$ & $0.1(0.1,0.1)$ & $0.14(0.1,0.355)$ & $0.125(0.1,0.6925)$ & 0.011 \\
\hline \multicolumn{6}{|c|}{$\begin{array}{l}\text { Data are presented as the mean } \pm \text { SD for normally distributed data or as the median (interquartile ranges) for } \\
\text { skewed data; CRP, }\end{array}$} \\
\hline
\end{tabular}

\section{The diagnostic accuracy of different marker}

The diagnostic performance of s-CRP and p-CRP values determined from a receiver operating characteristic (ROC) analysis were shown in Fig. 2 . The results showed that the AUC of s-CRP is $0.81(p<0.001)$ and AUC of pleural CRP is $0.783(p<0.001)$. p-CRP represent a very useful marker for the differentiation of malignant from infectious effusions. Using a cut-off point of $17.55 \mathrm{pg} / \mathrm{mL}$, pleural CRP presented $75.00 \%$ sensitivity and $83.90 \%$ specificity for the diagnosis 
of malignant from benign (Table 3). For s-CRP, at the cut-off point of $23.90 \mathrm{pg} / \mathrm{mL}$, s-CRP presented $71.00 \%$ sensitivity and $80.40 \%$ specificity for the diagnosis of malignant (Table 4). The combination of p-CRP and s-CRP produced the highest diagnostic accuracy (88.4\%) and higher specificity (72.4\%) in diagnosing infectious PE (Table 5).

Table 3

Diagnostic performance of pleural effusion CRP based on the ROC analysis

\begin{tabular}{|c|c|c|c|c|c|c|c|c|c|}
\hline & $\begin{array}{l}\text { Optimal } \\
\text { cut-off } \\
\text { point } \\
(\mathrm{pg} / \mathrm{mL})\end{array}$ & $\begin{array}{l}\text { Sensitivity } \\
(\%)\end{array}$ & $\begin{array}{l}\text { Specificity } \\
(\%)\end{array}$ & $+L R$ & -LR & $\begin{array}{l}\text { PPV } \\
(\%)\end{array}$ & $\begin{array}{l}\text { NPV } \\
(\%)\end{array}$ & AUC & $\begin{array}{l}\text { Accuracy } \\
\text { (\%) }\end{array}$ \\
\hline $\begin{array}{l}\text { Malignant vs } \\
\text { benign }\end{array}$ & 17.55 & 0.75 & 0.839 & 4.69 & 0.30 & $89.36 \%$ & $65 \%$ & 0.783 & $78.16 \%$ \\
\hline $\begin{array}{l}\text { Malignant vs } \\
\text { TB }\end{array}$ & 17.55 & 0.75 & 0.839 & 3.76 & 0.30 & $80.00 \%$ & $67 \%$ & 0.783 & $71.88 \%$ \\
\hline $\begin{array}{l}\text { Malignant vs } \\
\mathrm{EM} \text { and PE }\end{array}$ & 17.55 & 0.96 & 0.839 & 2.44 & 0.05 & $81.48 \%$ & $96.30 \%$ & 0.884 & $62.96 \%$ \\
\hline $\begin{array}{l}\text { TB vs } \mathrm{EM} \text { and } \\
\mathrm{PE}\end{array}$ & 45.35 & 0.788 & 0.696 & 3.48 & 0.30 & $72.73 \%$ & $77.42 \%$ & 0.796 & $75.47 \%$ \\
\hline
\end{tabular}

Table 4

Diagnostic performance of serum CRP based on the ROC analysis

\begin{tabular}{|c|c|c|c|c|c|c|c|c|c|}
\hline & $\begin{array}{l}\text { Optimal } \\
\text { cut-off } \\
\text { point } \\
(\mathrm{pg} / \mathrm{mL})\end{array}$ & $\begin{array}{l}\text { Sensitivity } \\
(\%)\end{array}$ & $\begin{array}{l}\text { Specificity } \\
(\%)\end{array}$ & +LR & -LR & $\begin{array}{l}\text { PPV } \\
(\%)\end{array}$ & $\begin{array}{l}\text { NPV } \\
(\%)\end{array}$ & AUC & $\begin{array}{l}\text { Accuracy } \\
(\%)\end{array}$ \\
\hline $\begin{array}{l}\text { Malignant vs } \\
\text { benign }\end{array}$ & 23.90 & 0.71 & 0.804 & 2.76 & 0.36 & $83.02 \%$ & $66.67 \%$ & 0.810 & $76.74 \%$ \\
\hline $\begin{array}{l}\text { Malignant vs } \\
\text { TB }\end{array}$ & 23.90 & 0.700 & 0.727 & 1.07 & 0.41 & $72.73 \%$ & $33.33 \%$ & 0.768 & $41 \%$ \\
\hline $\begin{array}{l}\text { Malignant vs } \\
\text { EM and PE }\end{array}$ & 26.70 & 0.71 & 0.952 & 2.44 & 0.3 & $70.97 \%$ & $95.65 \%$ & 0.897 & $81.48 \%$ \\
\hline $\begin{array}{l}\text { TB vs EM and } \\
\text { PE }\end{array}$ & 28.45 & 0.364 & 0.952 & 0.61 & 0.67 & $48.78 \%$ & $92.31 \%$ & 0.681 & $59.24 \%$ \\
\hline \multicolumn{10}{|c|}{$\begin{array}{l}\text { EM: empyema, PE: Parapneumonic, TB: Tuberculosis, +LR positive likelihood ratio, -LR negative likelihood ratio, PPV } \\
\text { positive predictive value, NPV negative predictive value, AUC area under the curve, ROC: receiver operating } \\
\text { characteristic curve, CRP, C-reactive protein; PCT, procalcitonin; }\end{array}$} \\
\hline
\end{tabular}


Table 5

Diagnostic performance of s-CRP and p-CRP combinations

\begin{tabular}{|c|c|c|c|c|c|c|c|}
\hline Cut-off value & $\begin{array}{l}\text { Sensitivity } \\
(\%)\end{array}$ & $\begin{array}{l}\text { Specificity } \\
(\%)\end{array}$ & $+\mathrm{LR}$ & -LR & $\begin{array}{l}\text { PPV } \\
\text { (\%) }\end{array}$ & $\begin{array}{l}\text { NPV } \\
(\%)\end{array}$ & $\begin{array}{l}\text { Accuracy } \\
\text { (\%) }\end{array}$ \\
\hline \multicolumn{8}{|l|}{$\begin{array}{l}\mathrm{p}-\mathrm{CRP}, 17.55 \mathrm{pg} / \mathrm{mL}+\mathrm{s}-\mathrm{CRP} \\
23.90 \mathrm{pg} / \mathrm{mL}\end{array}$} \\
\hline Malignant vs. benign & $88.40 \%$ & $72.40 \%$ & 3.20 & 0.16 & $67.4 \%$ & $80.8 \%$ & $81.9 \%$ \\
\hline Malignant vs TB & $72.00 \%$ & $80.77 \%$ & 3.74 & 0.35 & $78.26 \%$ & $75 \%$ & $76.47 \%$ \\
\hline Malignant vs EM and PE & $95.24 \%$ & $80.77 \%$ & 4.95 & 0.06 & $80.00 \%$ & $95.45 \%$ & $87.23 \%$ \\
\hline TB vs EM and PE & $95.24 \%$ & $28.00 \%$ & 4.95 & 0.45 & $52.63 \%$ & $95.45 \%$ & $58.70 \%$ \\
\hline
\end{tabular}

The analysis of p-PCT and s-PCT showed that both of the AUCs were < 0.5(data not shown), which suggests that both p-PCT and s-PCT are not useful for differentiation malignant from other type of effusions. However, p-PCT may be a useful marker in differentiating parapneumonic effusion from other type of effusions (excluding empyema).

\section{Discussion}

Exudative pleural effusion is a common clinical manifestation in pleura for patients with various respiratory disorders and its diagnosis of mainly depends on the pleural effusion-based examinations, including routine, biochemical, enzymology and pathological cytology analysis. However, the sensitivity and specificity of these tests are less satisfying. Pathological diagnosis, depended on pleural biopsy and other invasive operations, is regarded as the golden criteria in identifying the nature of pleura lesion, while the intolerance for invasive thoracoscope and the potential presence of underlying complications weaken its extensive clinical application, and its alternative scheme such as cytological examination may lead to misdiagnosis or missed diagnosis. Therefore, there exist a necessity to establish a diagnostic method with relatively high sensitivity and specificity. Additionally, the differential diagnosis of tuberculous pleurisy and parapneumonic pleural effusion often makes doctors face a dilemma, which results in the abusing of antibiotics on the one hand, and pleura hypertrophy on the other in a country like China with high incidence of tuberculosis.

Procalcitonin (PCT) is a peptide precursor for calcitonin released by the C-cells of the thyroid gland, being often used to distinguish bacterial infections from other diseases [13]. In the past, the diagnostic value of PCT in pleural effusion and serum has been investigated by several research groups. But the results are somewhat contradictory. For example, Porcel, et al opposed it that PCT has no value for the differential diagnosis of pleural effusions [7], while Lin and his colleague found that either pleural effusion or s-PCT were effective in diagnosing parapneumonic pleural effusion [8]. Furthermore, Khosla, et al investigated the diagnostic value of PCT in distinguishing infectious and noninfectious etiologies of pleural effusion, and the analysis results showed that PCT is a novel biomarker for diagnosing infectious pleural effusion [14]. Facing with these contradictory outcomes, here we examined the relationship between p-PCT and s- PCT levels in EPE from different groups and explored the various causes of pleural effusions. Interestingly, pleural PCT level was similar in four groups. As a classical marker of bacterial infection, s-PCT level is higher in the parapneumonic effusion group than that in tuberculosis and malignant group, but it was difficult to explain its absence of rapid increase in empyema group. The underlying mechanism may lie in the fact that those patients have received antibiotics and other treatments which can influence the expression of inflammatory factors both in serum and pleura. 
In the present study, we found that there was no significant difference in pleural PCT between 4 groups. Overall, whether p-PCT or s-PCT is of no diagnostic value for judging the etiology of pleural effusion disease, which may be related to the secretion location of PCT and the way of PCT entering the thoracic cavity. It may also be due to the disintegration of a mass of necrotic cells in the pleural cavity, releasing many inflammatory cytokines, and in turn affecting the metabolism of PCT in pleural effusion.

As for another classical inflammatory indicator, CRP, its expression in pleural effusion might largely depend on its infiltration from thoracic wall vessels into pleural cavity, while there is a positive correlation between CRP in pleural effusion and s-CRP [15]. Similar to other previous studies, we found that p-CRP levels were higher in infectious pleural effusions, especially in parapneumonic effusion and empyema compared with non-infectious effusions. This result indicated its promising value of p-CRP measurement in differentiating benign and malignant pleural effusions. It is worth noting that combinative examination of $\mathrm{p}$-CRP and s-CRP can distinguish pleural fluid from benign and malignant diseases with a higher accuracy compared to examination of just p-CRP or s-CRP. To evaluate the diagnostic value of two kinds of CRPs, we performed ROC analysis, revealing that the combined pleural effusion CRP and s-CRP was more valuable and effective than p-CRP or s-CRP alone, which improved the diagnostic sensitivity, specificity and accuracy further.

However, there are several limitations in the present study. Firstly, the gold standard for diagnosing with lymphocyte predominance pleural diseases is pleural biopsy. However, most of the patients in this study did not carry out the examination due to various factors, such as the patients' refusal, clinical limitations, and expense-related inevitable affairs. The clinical diagnosis mainly depends on the comprehensive interpretations of clinical physicians based on symptoms, signs and various existing laboratory results. Secondly, some malignant patients may have obstructive pneumonia, but we do not have a more accurate grouping, which may also affect the analysis results. In summary, our results showed that combined analysis of CRP in serum and pleural effusion may be useful for differential diagnosis of EPE with higher diagnostic accuracy, sensitivity and specificity.

\section{Conclusions}

The data support the close relationship between combined analysis of p-CRP with s-CRP and effective and accurate differential diagnosis of EPE, due to its higher sensitivity and specificity. However, as a highly sensitive marker to diagnose bacterial infections, neither p-PCT nor s-PCT, showed correlations with the differential diagnosis of EPE.

\section{Abbreviations}

ADA『adenosine deaminase

CRP: C-reactive protein

LDH®lactate dehydrogenase

PCT: procalcitonin

PE囚Pleural effusion

ROC\receiver operating characteristic

WCC $₫$ White cell count

\section{Declarations}




\section{Ethics approval and consent to participate}

All methods of this study were carried out in accordance with the relevant guidelines and regulations of the Fourth Military Medical University.

We got the review approval document of the Medical Ethics Committee of the first affiliated hospital of the Fourth military Medical University (No. KY20202098-C-1).

\section{Consent for publication}

Not applicable

\section{Availability of data and materials}

The datasets used and/or analyzed in the present study are available from the corresponding author upon reasonable request.

\section{Competing interests}

The authors declare that they have no competing interests.

\section{Funding}

This work was supported by XiJing Hospital Promoting Project (No. XJZT18ML23).

\section{Authors' Contributions:}

Manuscript writing: Shuo-yao Qu; Collection of the cases: Shuo-yao Qu and Shuo Wu; Data statistics: Zhang Yong; Follow-up of cases: Ming-Ming Wang, Ling-Li Liu, Xue-min Yang, Hui-Liang Shan, Juan-li Yang, Pei Chen; Conception and experiment design: Xin-Yu Ti, Li-qiang Song.

\section{Acknowledgements}

Not applicable.

\section{Authors' information (optional)}

Department of Pulmonary and Critical Care Medicine, Xijing Hospital, Fourth Military Medical University, Xi'an, 710032 China

\section{References}

1. Richard W Light. Parapneumonic Effusions and Empyema. Proc Am Thorac Soc. 2006;3:75-80. 
2. Tarn AC, Lapworth R. BTS guidelines for investgtion of unilateral pleural effusion in adults. Thorax. 2004; 59: 3589.

3. J D Santotoribio, A León-Justel, C Delgado-Pecellín, J M Guerrero. What Are the Biochemical Parameters of Pleural Fluid That Best Identify Parapneumonic ffusions?Ann Clin Biochem. 2009;46:176-7.

4. José Manuel Porcel , Manuel Vives, Aureli Esquerda, Agustín Ruiz. Usefulness of the British Thoracic Society and the American College of Chest Physicians Guidelines in Predicting Pleural Drainage of Non-Purulent Parapneumonic Effusions. Respir Med. 2006;100:933-7.

5. Z D Daniil , E Zintzaras, T Kiropoulos, A I Papaioannou, A Koutsokera, A Kastanis, et al. Discrimination of exudative pleural effusions based on multiple biological parameters. Eur Respir J. 2007 Nov;30(5):957-64.

6. Yang Y, Xie J, Guo F, Longhini F, Gao Z, Huang Y, et al. Combination of C-reactive protein, procalcitonin and sepsisrelated organ failure score for the diagnosis of sepsis in critical patients. Ann Intensive Care. 2016;6(1):51.

7. Gabay C, Kushner I. Acute-phase proteins and other systemic responses to inflammation. N. Engl. J. Med. 1999;340: 448-54.

8. Assicot M, Gendrel D, Carsin H, Raymond J, Guilbaud J, Bohuon C. High serum procalcitonin concentrations in patients with sepsis and infection. Lancet. 1993;341:515-8.

9. Porcel JM, Vives M, Cao G, Bielsa S, Ruiz-González A, Martínez-Iribarren A, et al.Biomarkers of infection for the differential diagnosis of pleural effusions. Eur Respir J. $2009 ; 34(6): 1383-9$.

10. Meng-Chih Lin, Yung-Che Chen , Jiun-Ting Wu , Yang-Chin Ko, Chin-Chou Wang. Diagnostic and Prognostic Values of Pleural Fluid Procalcitonin in Parapneumonic Pleural Effusions. Chest.2009;136:205-211.

11. Huiling Li, Liyan Huang, Hailing Tang, Nanshan Zhong, Jianhang He .Pleural fluid carcinoembryonic antigen as a biomarker for the discrimination of tumor-related pleural effusion .Clin Respir J. 2017;11:881-886.

12. Porcel JM, Light RW. Diagnostic approach to pleural effusion in adults. Am Fam Physician. 2006 Apr 1;73(7):121120.

13. Brunkhorst R, Eberhardt OK, Haubitz M, Brunkhorst FM.

Procalcitonin for discrimination between activity of systemic autoimmune disease and systemic bacterial infection. Intensive Care Med. 2000;26 Suppl 2: S199-201.

14. Rahul Khosla, Shikha G Khosla, Kenneth L Becker, Eric S Nylen. Pleural fluid procalcitonin to distinguish infectious from noninfectious etiologies of pleural effusions. J Hosp Med. 2016; 11:363-5.

15. Castaño Vidriales JL, Amores Antequera C. Use of pleural fluid C-

Reactive protein in laboratory diagnosis of pleural effusions. Eur J Med. 1992;1:201-7.

\section{Figures}





Figure 1

CRP and PCT of Pleural fluid and serum levels in the different diagnostic subgroups. (A)Pleural fluid CRP, (B)Serum CRP, (C)Pleural fluid PCT and (D)Serum PCT levels in the different diagnostic subgroups. Individual values are plotted. Bars represent the means of the values, and $p$-values are shown between groups with statistically significant differences. *: $p$ $<0.05, * *$ : $p<0.01$, vs Malignant group. \#: $p<0.05, \# \#$ : $p<0.01$, vs Tuberculous group. 


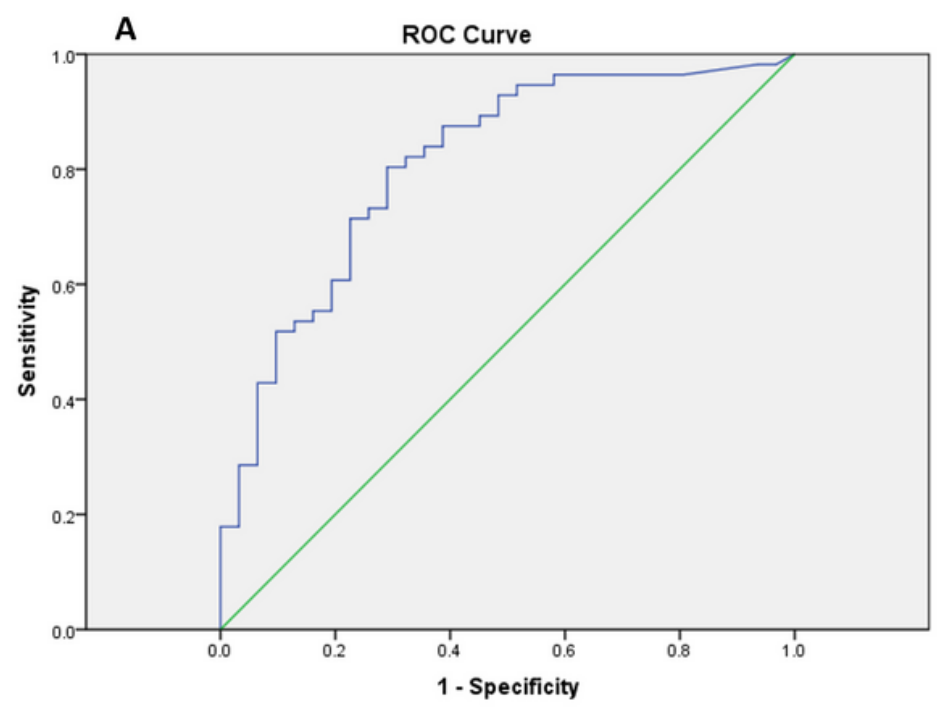

Diagonal segments are produced by ties.

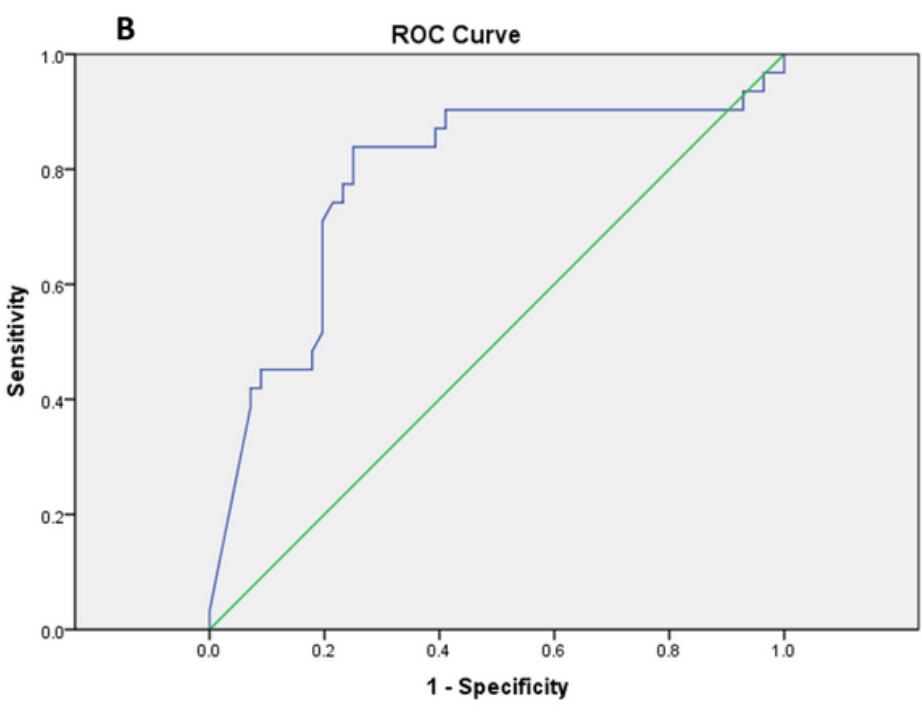

Diagonal segments are produced by ties.

\section{Figure 2}

ROC curve for the diagnosis of EPE. Receiver operator characteristic (ROC) analysis curves of $p$-CRP and s-CRP levels for differentiating malignant from infectious effusions. (A) ROC curve of s-CRP levels for differentiating parapneumonic pleural effusions, and (B) ROC curve of $p$-CRP levels for differentiating parapneumonic pleural effusions. The AUC for $p$ CRP is $0.810(p<0.001)$, and for $s-C R P$ is $0.783(p<0.001)$. AUC = area under the curve, ROC = receiver operating characteristic. 